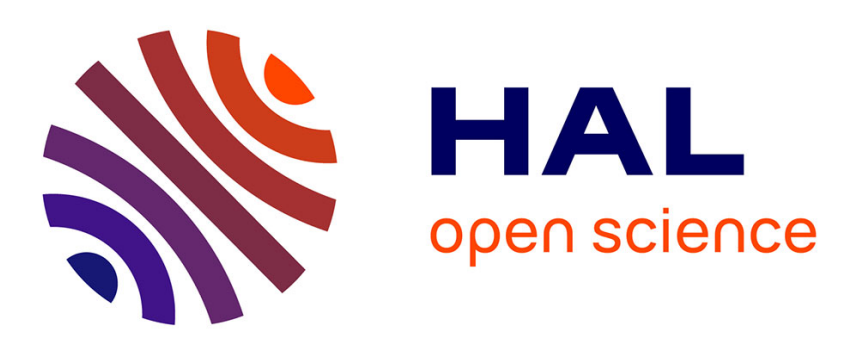

\title{
A test of the I2 ground state molecular constants deduced from Fourier absorption spectroscopy: the Wood's resonance series
}

S. Gerstenkom, P. Luc, J. Verges

\section{- To cite this version:}

S. Gerstenkom, P. Luc, J. Verges. A test of the I2 ground state molecular constants deduced from Fourier absorption spectroscopy: the Wood's resonance series. Revue de Physique Appliquée, 1983, 18 (2), pp.81-86. 10.1051/rphysap:0198300180208100 . jpa-00245075

\section{HAL Id: jpa-00245075 https://hal.science/jpa-00245075}

Submitted on 1 Jan 1983

HAL is a multi-disciplinary open access archive for the deposit and dissemination of scientific research documents, whether they are published or not. The documents may come from teaching and research institutions in France or abroad, or from public or private research centers.
L'archive ouverte pluridisciplinaire HAL, est destinée au dépôt et à la diffusion de documents scientifiques de niveau recherche, publiés ou non, émanant des établissements d'enseignement et de recherche français ou étrangers, des laboratoires publics ou privés. 


\title{
A test of the $I_{2}$ ground state molecular constants deduced from Fourier absorption spectroscopy : the Wood's resonance series
}

\author{
S. Gerstenkorn, P. Luc and J. Vergès \\ Laboratoire Aimé Cotton (*), C.N.R.S. II, Bâtiment 505, 91405 Orsay Cedex, France
}

(Reçu le 20 septembre 1982, révisé le 16 novembre, accepté le 18 novembre 1982)

\begin{abstract}
Résumé. - L'étude du spectre d'absorption de la molécule de l'iode dans le proche infrarouge entre 11600 et $12600 \mathrm{~cm}^{-1}$ nous a permis d'identifier cinq nouvelles bandes $\left(0, v^{\prime \prime}\right)$ où $15 \leqslant v^{\prime \prime} \leqslant 19$. On dispose dès lors d'un ensemble cohérent de constantes moléculaires décrivant les vingt premiers niveaux de l'état fondamental X ${ }^{1} \Sigma_{0 \mathrm{~g}}^{+}$, établies uniquement à l'aide de mesures effectuées par spectroscopie de Fourier en absorption. La comparaison entre les nombres d'ondes mesurés antérieurement à l'aide d'étalons Fabry-Perot n'est que partiellement satisfaisante. En particulier, les valeurs mesurées correspondant aux premiers membres de la série de Wood appartenant au système (B-X) doivent être corrigées; cette conclusion est également confirmée par une mesure indépendante du nombre d'ondes de la raie pompe $\mathrm{R} 33(25,0)$ de la série de Wood, inscrite dans le profil complexe de la raie verte du mercure.

Abstract. - Fourier absorption spectroscopy studies of the iodine molecule in the near infrared region between $11600-12600 \mathrm{~cm}^{-1}$ enabled us to detect five $\left(0, v^{\prime \prime}\right)$ bands with $15 \leqslant v^{\prime \prime} \leqslant 19$. Thus, an homogeneous set of molecular constants, based only on Fourier absorption measurements, describing the twenty first low lying vibrational level of the ground state $\mathrm{X}^{1} \Sigma_{0 \mathrm{~g}}^{+}$, are now available. Only partial agreement was found between $a$ priori calculated wavenumbers of the Wood's green line resonance series (B-X system) based on the new set of molecular constants and earlier experimental values deduced from Fabry-Perot interferometric measurements. In particular the FabryPerot experimental values of the first members of Wood's series must be corrected; this conclusion is also confirmed by an independent measurement of the pump line of Wood's series, $R 33(25,0)$, located inside the complex profile of the mercury green line.
\end{abstract}

1. Introduction. - In 1964, Rank and Rao [1] determined a set of molecular constants of the iodine ground state $\mathrm{X}^{1} \Sigma_{0 \mathrm{~g}}^{+}$using several sources of data including the wavenumber measurements of Wood's mercury green line resonance doublets. Among these doublets $\left(\mathrm{R}\left(J_{r}-1\right), \mathrm{P}\left(J_{r}+1\right)\right)\left(v^{\prime}, v^{\prime \prime}\right)$ where $v^{\prime}=25$ and $v^{\prime \prime}$ is the running term (Fig. 1), fifteen were measured by means of Fabry-Perot etalons (Rank and Baldwin [2]); until now these interferometric measurements (denoted $\sigma_{\text {exp }}^{\text {F.P.) }}$ of R. and B. [2] were considered as fundamental data in our knowledge of the iodine spectrum [3]. However, as early as 1970 , in course of the reanalysis of the ground state of iodine, R. J. Le Roy [4] found it necessary to shift the value of the " vibrational ladder " wavenumber $\mathbf{R} 33(25,0)$ resulting from the Rank and Rao analysis by $0.016 \mathrm{~cm}^{-1}$ [4].

On another hand, precise molecular constants

(*) Laboratoire associé à l'Université Paris-Sud.

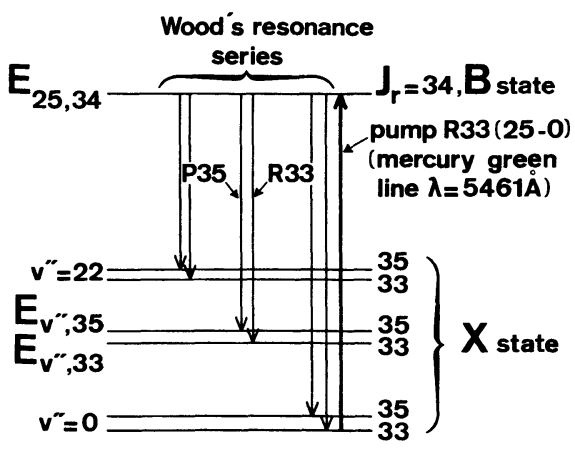

Fig. 1. - Schematic diagram of Wood's resonance series induced by the mercury green line. Fabry-Perot measurements were made up to $v^{\prime \prime}=22$ [2].

describing the $\mathrm{I}_{\mathbf{2}}(\mathrm{B}-\mathrm{X})$ system were recently published : in particular the molecular constants of the $v^{\prime}=25$ vibrational level of the $B$ state [5] and the constants of the fifteen first vibrational levels up to $v^{\prime \prime}=14$ of the 
Table I. - Number of assigned lines in the $\mathrm{R}$ and $\mathrm{P}$ branches in each analysed band.

\begin{tabular}{|c|ccc|ccc|c|c|}
\hline $\begin{array}{c}\text { Bands } \\
\left(v^{\prime}, v^{\prime \prime}\right)\end{array}$ & $J_{\boldsymbol{m}}$ & $\begin{array}{c}\text { P Branch } \\
J_{\text {MAX }}\end{array}$ & $N_{\mathbf{P}}$ & $J_{\boldsymbol{m}}$ & $\begin{array}{c}\text { R Branch } \\
J_{\text {MAX }}\end{array}$ & $N_{\mathbf{R}}$ & $N_{\mathbf{P}}+N_{\mathbf{R}}$ & $\begin{array}{c}\text { S.D. (cm } \\
\sigma_{\text {cal }}-\sigma_{\text {meas }}\end{array}$ \\
\hline $0-15$ & 17 & 165 & 144 & 14 & 175 & 145 & 289 & 0.0019 \\
$0-16$ & 44 & 172 & 121 & 18 & 172 & 120 & 241 & 0.0021 \\
$0-17$ & 33 & 155 & 84 & 35 & 155 & 91 & 175 & 0.0023 \\
$0-18$ & 29 & 174 & 132 & 29 & 173 & 129 & 261 & 0.0029 \\
$0-19$ & 32 & 114 & 57 & 28 & 121 & 56 & 113 & 0.0034 \\
\hline
\end{tabular}

$\mathrm{X}$ state [6]. In the study presented here, we have extended the determination of the molecular constants of the X state up to $v^{\prime \prime}=19$, made possible by the recording of the Fourier absorption spectrum of iodine in the $11600-12600 \mathrm{~cm}^{-1}$ range. Thus, a coherent set of molecular constants describing the twenty first vibrational levels of the $\mathrm{X}$ state based on the Fourier absorption measurements, is now available. Accordingly, a valuable test of the reliability of these molecular constants can be achieved by comparing the experimental $\sigma_{\text {exp }}^{\text {F.P. }}$ values to the a priori calculated ones $\left(\sigma_{\mathrm{cal}}^{\text {Fourier }}\right)$ deduced from the Fourier data. This comparison shows, surprisingly, that there exists a discrepancy of 0.010 to $0.020 \mathrm{~cm}^{-1}$ between $\sigma_{\text {exp }}^{\text {F.P. and }} \sigma_{\text {cal }}^{\text {Fourier }}$ for the five first members of the doublet series and that the "vibrational ladder " wavenumber determinated by Rank and Rao has to be corrected by an amount of $0.030 \mathrm{~cm}^{-1}$. This disagreement of $0.030 \mathrm{~cm}^{-1}$, which is one order of magnitude larger than the uncertainties encountered in conventional interferometric measurements, led us to undertake an independent measurement of the wavenumber of the $R 33(25,0)$ transition; this measurement, based on the particular pattern of the hyperfine structure of the mercury green line, confirms both the necessity to introduce a shift [4] and the validity of the molecular constants deduced from the Fourier data. These molecular constants are given below, after a brief description of the experimental set-up which permitted us to extend the recording of the iodine absorption spectrum to the near infrared, where the $\left(0, v^{\prime \prime}\right)$ progression from $v^{\prime \prime}=15$ to $v^{\prime \prime}=19$, is located.

2. Experimental set-up. - An oven containing a quartz absorption cell $2 \mathrm{~m}$ long was built. The cell was heated to a temperature of $500{ }^{\circ} \mathrm{C}$; the iodine pressure inside the cell was kept to a pressure of about 15 torr by means of a side arm maintained at $80^{\circ} \mathrm{C}$. A $200 \mathrm{~W}$ tungsten iodine quartz lamp provided the background. The interferograms contain about $4 \times 10^{5}$ points corresponding to a total path difference of $54 \mathrm{~cm}$, each step being equal to $4 / 10 \sigma_{\mathrm{Xe}}$, where $\sigma_{\mathrm{Xe}}=2850.6401 \mathrm{~cm}^{-1}$ is the wavenumber of the reference line whose width is narrowed by stimulated emission in a xenon source. The instrumental width of the Fourier spectrometer was fixed to about $0.010 \mathrm{~cm}^{-1}$ and the recorded width of the iodine lines did not exceed $0.025 \mathrm{~cm}^{-1}$. Despite the relatively high temperature $(773 \mathrm{~K})$ of the absorption cell, the width of the observed lines was comparable to the width of the iodine lines observed in the visible range [7] for which the cell temperature was only $T=294 \mathrm{~K}$. This effect results from the fact that, to a first approximation, the iodine width of absorption lines is not limited by the Doppler effect but by the existence of an unresolved hyperfine structure, the total width of which is about $0.025 \mathrm{~cm}^{-1}$ [8].

3. Results. - 3.1 BAND BY BAND ANALYSIS. In the range of study, $11600-12600 \mathrm{~cm}^{-1}$, wavenumbers of about 2900 lines were measured. From these data five $\left(0, v^{\prime \prime}\right)$ bands were extracted and analysed (the remaining data belongs to either the (A-X)

Table II. - Molecular constants (in $\mathrm{cm}^{-1}$ units) determined from the global fit of the data, describing the twenty first vibrational levels of the ground state $\mathrm{X}^{1} \Sigma_{0 \mathrm{~g}}^{+}$of iodine.

\begin{tabular}{|r|c|c|c|c|}
\hline$v^{\prime \prime}$ & $G\left(v^{\prime \prime}\right)-G(0)$ & $10 \times B\left(v^{\prime \prime}\right)$ & $10^{8} \times D\left(v^{\prime \prime}\right)$ & $-10^{15} \times H\left(v^{\prime \prime}\right)$ \\
\hline 0 & 0.0 & 0.373112007 & 0.454744 & 0.5157 \\
1 & 213.3014 & 0.371966941 & 0.457218 & 0.5320 \\
2 & 425.3735 & 0.370815743 & 0.459753 & 0.5528 \\
3 & 636.2101 & 0.369658124 & 0.462374 & 0.5764 \\
4 & 845.8037 & 0.368493803 & 0.465096 & 0.6013 \\
5 & 1054.1462 & 0.367322503 & 0.467923 & 0.6269 \\
6 & 1261.2289 & 0.366143952 & 0.470857 & 0.6530 \\
7 & 1467.0429 & 0.364957878 & 0.473898 & 0.6798 \\
8 & 1671.5791 & 0.363764009 & 0.477048 & 0.7077 \\
9 & 1874.8284 & 0.362562067 & 0.480311 & 0.7372 \\
10 & 2076.7814 & 0.361351772 & 0.483692 & 0.7688 \\
11 & 2277.4284 & 0.360132831 & 0.487203 & 0.8030 \\
12 & 2476.7595 & 0.358904943 & 0.490856 & 0.8398 \\
13 & 2674.7640 & 0.357667794 & 0.494663 & 0.8792 \\
14 & 2871.4310 & 0.356421053 & 0.498637 & 0.9205 \\
15 & 3066.7489 & 0.355164374 & 0.502783 & 0.9625 \\
16 & 3260.7054 & 0.353897388 & 0.507100 & 1.0032 \\
17 & 3453.2884 & 0.352618807 & 0.511574 & 1.0400 \\
18 & 3644.4857 & 0.351330910 & 0.516171 & 1.0691 \\
19 & 3834.2856 & 0.350030560 & 0.520834 & 1.0858 \\
\hline
\end{tabular}


Table III. - Dunham expansion coefficients $Y_{i 0}, Y_{i 1}, Y_{i 2}$ and $Y_{i 3}$ of the ground state $X^{1} \Sigma_{0 \mathrm{~g}}^{+}$

\begin{tabular}{|c|c|c|c|}
\hline$G\left(v^{\prime \prime}\right)=\Sigma Y_{i 0}(v+1 / 2)^{i}$ & $B\left(v^{\prime \prime}\right)=\Sigma Y_{i 1}(v+1 / 2)^{i}$ & $D\left(v^{\prime \prime}\right)=\Sigma Y_{i 2}(v+1 / 2)^{i}$ & $H\left(v^{\prime \prime}\right)=\Sigma Y_{i 3}(v+1 / 2)^{i}$ \\
\hline$+0.214526755+03$ & $+0.373682334-001$ & $+0.453518759-008$ & $-0.510152790-015$ \\
$-0.611938186+00$ & $-0.113922247-003$ & $+0.245172014-010$ & $-0.904728688-017$ \\
$-0.235606136-03$ & $-0.283866568-006$ & $-0.428646554-013$ & $-0.451982759-017$ \\
$-0.140816912-03$ & $-0.521237377-008$ & $+0.108340667-012$ & $+0.618671293-018$ \\
$+0.943318488-05$ & $+0.582010316-010$ & $-0.109632940-013$ & $-0.416460060-019$ \\
$-0.344433981-06$ & $-0.195761456-011$ & $+0.554529098-015$ & $+0.976640426-021$ \\
$+0.490779344-08$ & & $-0.103723995-016$ & \\
\hline
\end{tabular}

system [9], or to weak $\left(1, v^{\prime \prime}\right)$ bands of the (B-X) system). Table I gives the number of assigned lines for each band as well as the minimum and the maximum values detected in each $\mathbf{R}$ and $\mathbf{P}$ branch. The total number of assigned lines is 1079 .

3.2 Global fit of the Data. - These 1079 lines were added to the previous data describing the (B-X) system up to $v^{\prime \prime}=14[5,6]$. Then a global fit was done following the method described in recent papers $[3,5]$. It is enough to recall here that in this method the CDC (Centrifugal Distortion Constants) values $D, H, L . .$. are not " experimental " values but are those obtained from theory $[10,11]$, and that the fitting process concerns only the vibrational and rotational constants. Table II contains the resulting molecular constants $G_{v^{\prime \prime}}, B_{v^{\prime \prime}}, D_{v^{\prime \prime}}, H_{v^{\prime \prime}}$ of the twenty
Table IV. - Molecular constants (in $\mathrm{cm}^{-1}$ units) of the ground vibrational level $v^{\prime}=0$ and the $v^{\prime}=25$ vibrational level of the excited state $\mathrm{B}\left({ }^{3} \Pi_{0 \mathrm{u}}^{+}\right)$.

\begin{tabular}{|l|c|c|}
\hline Constants & $v^{\prime}=0$ & $v^{\prime}=25$ \\
\hline$\sigma_{v^{\prime}, 0}$ & 15724.5867 & 18320.6533 \\
$B_{v^{\prime}}$ & 0.028925682 & 0.024137818 \\
$D_{v^{\prime}}$ & $0.623207-008$ & $0.122502-007$ \\
$H_{v^{\prime}}$ & $-0.23597-014$ & $-0.19244-013$ \\
$L_{v^{\prime}}$ & $-0.301-020$ & $-0.624-019$ \\
$M_{v^{\prime}}$ & $-0.110-025$ & $-0.601-024$ \\
\hline
\end{tabular}

first vibrational levels of the ground state $X^{1} \Sigma_{0 \mathbf{g}^{\text {. }}}^{+}$ Table III gives the corresponding $Y_{i l}$ coefficients of the Dunham expansion series, valid for $0 \leqslant v^{\prime \prime} \leqslant 19$.

Table V. - Comparison between a priori calculated wavenumbers of the mercury green line resonance series and experimental ones.

\begin{tabular}{|c|c|c|c|c|c|c|}
\hline$v^{\prime \prime}$ & $\begin{array}{l}\sigma_{\text {exp }}^{\text {F.P. }}[2] \\
\left(\mathrm{cm}^{-1}\right)\end{array}$ & $\begin{array}{c}\text { P Branch } \\
\underset{\sigma_{\text {cal }}^{\text {Fourier }}}{\left(\mathrm{cm}^{-1}\right)}\end{array}$ & $\begin{array}{c}\sigma_{\text {exp }}^{\text {F.P. }}-\sigma_{\text {cal }}^{\text {Fourier }} \\
\left(10^{-3} \mathrm{~cm}^{-1}\right)\end{array}$ & $\begin{array}{l}\sigma_{\text {exp }}^{\text {F.P. }}[2] \\
\left(\mathrm{cm}^{-1}\right)\end{array}$ & 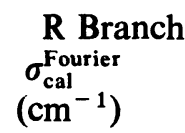 & $\begin{array}{c}\sigma_{\text {exp }}^{\text {F.P. }}-\sigma_{\text {cal }}^{\text {Fourier }} \\
\left(10^{-3} \mathrm{~cm}^{-1}\right)\end{array}$ \\
\hline 0 & & & & 18307.471 & 5025 & -31.5 \\
\hline 1 & 18089.179 & 1979 & -18.9 & 094.309 & 3296 & -20.6 \\
\hline 2 & - & & & - & & \\
\hline 3 & 17666.563 & 5802 & -17.2 & 17671.664 & 6800 & -16.0 \\
\hline 4 & 457.122 & 1333 & -9.6 & 462.205 & 2170 & -12.0 \\
\hline 5 & 248.938 & 9385 & -0.5 & 253.992 & 0060 & -14.0 \\
\hline 6 & 041.999 & 0043 & $-\quad 5.3$ & 047.054 & 0556 & -1.6 \\
\hline 7 & - & & & - & & \\
\hline 8 & 16631.943 & 9541 & -11.1 & 16636.969 & 9725 & -3.5 \\
\hline 9 & - & & & - & & \\
\hline 10 & 227.052 & 0559 & $-\quad 3.9$ & 232.036 & 0410 & $-\quad 5.0$ \\
\hline 11 & 026.561 & 5625 & -1.5 & 031.524 & 5307 & -6.7 \\
\hline 12 & 15827.387 & 3862 & +0.8 & 15832.335 & 3375 & -2.5 \\
\hline 13 & 629.539 & 5376 & +1.4 & 634.470 & 4718 & -1.8 \\
\hline 14 & - & & & - & & \\
\hline 15 & 237.870 & 8683 & +1.7 & 242.770 & 7680 & +2.0 \\
\hline 16 & - & & & - & & \\
\hline 17 & 14851.651 & 6495 & +1.5 & 14856.520 & 5140 & +6.0 \\
\hline 18 & 660.635 & 6146 & +11.6 & 665.479 & 4614 & +18.4 \\
\hline 19 & - & & & - & & \\
\hline
\end{tabular}


The constants of table II, together with the molecular constants of the vibrational level $v^{\prime}=25$ of the B state given in table IV are necessary to calculate the wavenumbers of Wood's resonance series.

4. Comparison between calculated wavenumbers and Rank and Baldwin's experimental measurements. The rotation-vibration energy of a diatomic molecule is given by the expression :

$$
\begin{aligned}
E_{v, J}=\sigma_{0, v}+B_{v} K-D_{v} K^{2} & +H_{v} K^{3}+ \\
& +L_{v} K^{4}+M_{v} K^{5}+\cdots
\end{aligned}
$$

where $\sigma_{0, v}=T_{e}+G_{v}$ is the vibronic energy of the rotationless molecule in vibrational state $v ; B_{v}$ is the corresponding rotational constant ; $D_{v}, H_{v}, L_{v}, M_{v} \ldots$ are the CDC constants and $K=J(J+1)$. The resonance doublets induced by the radiation of the mercury green line are (Fig. 1) :

$$
\begin{aligned}
& \sigma\left(\mathrm{R}\left(J_{r}-1\right)\right)\left(v^{\prime}, v^{\prime \prime}\right)=E_{25,34}^{\prime}-E_{v^{\prime \prime}, 33} \\
& \sigma\left(\mathrm{P}\left(J_{r}+1\right)\right)\left(v^{\prime}, v^{\prime \prime}\right)=E_{25,34}^{\prime}-E_{v^{\prime \prime}, 35} .
\end{aligned}
$$

More explicitly : the energy of the upper level $E_{25,34}^{\prime}$ is equal to

$$
\begin{aligned}
E_{25,34}^{\prime}=\sigma_{0,25}^{\prime}+B_{25}^{\prime}\left[J_{r}\left(J_{r}+1\right)\right] & - \\
& -D_{25}^{\prime}\left[J_{r}\left(J_{r}+1\right)\right]^{2}
\end{aligned}
$$

and the two lower levels $E_{v^{\prime \prime}, 33}$ and $E_{v^{\prime \prime}, 35}$ are respectively equal to

$$
\begin{gathered}
E_{v^{\prime \prime}, 33}=G_{v^{\prime \prime}}+B_{v^{\prime \prime}}\left[\left(J_{r}-1\right)\left(J_{r}\right)\right]- \\
-D_{v^{\prime \prime}}\left[\left(J_{r}-1\right)\left(J_{r}\right)\right]^{2} \\
E_{v^{\prime \prime}, 35}=G_{v^{\prime \prime}}+B_{v^{\prime \prime}}\left[\left(J_{r}+1\right)\left(J_{r}+2\right)\right]- \\
-D_{v^{\prime \prime}}\left[\left(J_{r}+1\right)\left(J_{r}+2\right)\right]^{2}
\end{gathered}
$$

where $J_{r}=34$. (The contribution of centrifugal constants of higher order than $D$ being negligible : for example the contributions of $-H_{19}^{\prime \prime}\left[J_{r}\left(J_{r}+1\right)\right]^{3}$ and $-H_{25}^{\prime}\left[J_{r}\left(J_{r}+1\right)\right]^{3}$ are respectively equal to $2 \times 10^{-5}$ and $\left.4 \times 10^{-3} \mathrm{~cm}^{-1}\right)$. In column 2 of table $\mathrm{V}$ are given the experimental values (denoted $\left.\sigma_{\text {exp }}^{\text {F.P. }}\right)$. Calculated wavenumbers of the doublets are given in column $3\left(\sigma_{\text {cal }}^{\text {Fourier }}\right)$; the difference $\left(\sigma_{\text {exp }}^{\text {F.P. }}-\right.$ $\sigma_{\text {cal }}^{\text {Fourier }}$ ) of interest are listed in columns 4 and 7 for each $\mathbf{P}$ and $\mathbf{R}$ branch. The experimental values of the resonance lines wavenumbers connected to the $v^{\prime \prime}=0,1,3,4$ levels are larger by an amount decreasing from $0.032 \mathrm{~cm}^{-1}$ to $0.012 \mathrm{~cm}^{-1}$. Apart from the doublet P35, R33 $(25,18)$ which consists of weak lines, the remaining differences show a satisfactory agreement $\left( \pm 0.005 \mathrm{~cm}^{-1}\right.$ in average) between the two sets of experimental and calculated values, without systematic trends. (Some lines of the doublet series, those connected to the $v^{\prime \prime}=2,7,9,14$ and 19 were not observed [2], because of their weak Franck-Condon Factors; on another hand the last doublets (with $v^{\prime \prime}=20$ and 22) observed by $R$. and $B$. are outside the range of the vibrational $v^{\prime \prime}$ levels detectable in our absorption work.)

To summarize, the comparison leads to a paradoxical situation : the wavenumbers of doublets corresponding to the lower vibrational $v^{\prime \prime}$ levels of the ground state are systematically in disagreement with the calculated ones; this was not expected because in absorption the molecular constants of the lower $v^{\prime \prime}$ levels are, indeed, better defined. It follows that either the measurements of $R$. and $B$. must partially be corrected, as suggested by Le Roy [4], or several molecular constants determined in course of our Fourier absorption work are to be revised. To decide between these two possibilities we have undertaken an independent measurement of the "vibrational ladder " line $\mathbf{R} 33(25,0)$, for which the discrepancy is maximum $\left(0.030 \mathrm{~cm}^{-1}\right)$.

\section{Absorption of the mercury green line by iodine} vapour. - Figure 2 shows the emission spectrum of the mercury green line and the iodine absorption spectrum observed in the same spectral region. The recorded profile of the green line is taken in reference [12] $\left.{ }^{1}\right)$, and the iodine absorption spectrum is the one published in the iodine atlas [7]; in addition, the assignments of the iodine lines are given. The $a$ priori relative position of the mercury emission spectrum versus the iodine one was made possible by the precise absolute wavenumber measurement of all the hyperfine components of the mercury green line made by $\mathrm{K}$. Burns and K. Adams $[13,14]$ and to the calculated wavenumbers of the $\mathrm{R} 33(25,0)$ line $(\sigma(\mathrm{R} 33)=$ $18307.5025 \mathrm{~cm}^{-1}$, table $\mathrm{V}$, column 3). The key of our experiment now becomes obvious : inspection of figure 2 shows that the position of the $A$ component belonging to the 199 mercury isotope prevents this component to be appreciably affected by an absorption of iodine vapour. This is not the case for the central peak of the green line which is absorbed more or less by the transition $\mathrm{R} 33(25,0)$ and $\mathrm{P} 109(27,0)$. If the absolute wavenumber of the hyperfine component $A$ is known, which is the case [13,14], then the distance between the absorption peak of the $R 33(25,0)$ line (detected inside the profile of the green line) and the hyperfine component $A$, gives directly the absolute value of the $R 33(25,0)$ transition.

Figure 3 shows three Fourier spectroscopy recordings :

a) profile of the mercury green line alone, emitted by a Phillips lamp whose glass envelope was taken off in order to avoid self absorption ;

( $\left.{ }^{1}\right)$ This report [12] is written in french. An excellent translation in english can be found in : Analele Universitatii Bucaresti, Fizica XXIX, 1980, pages 21-29. 


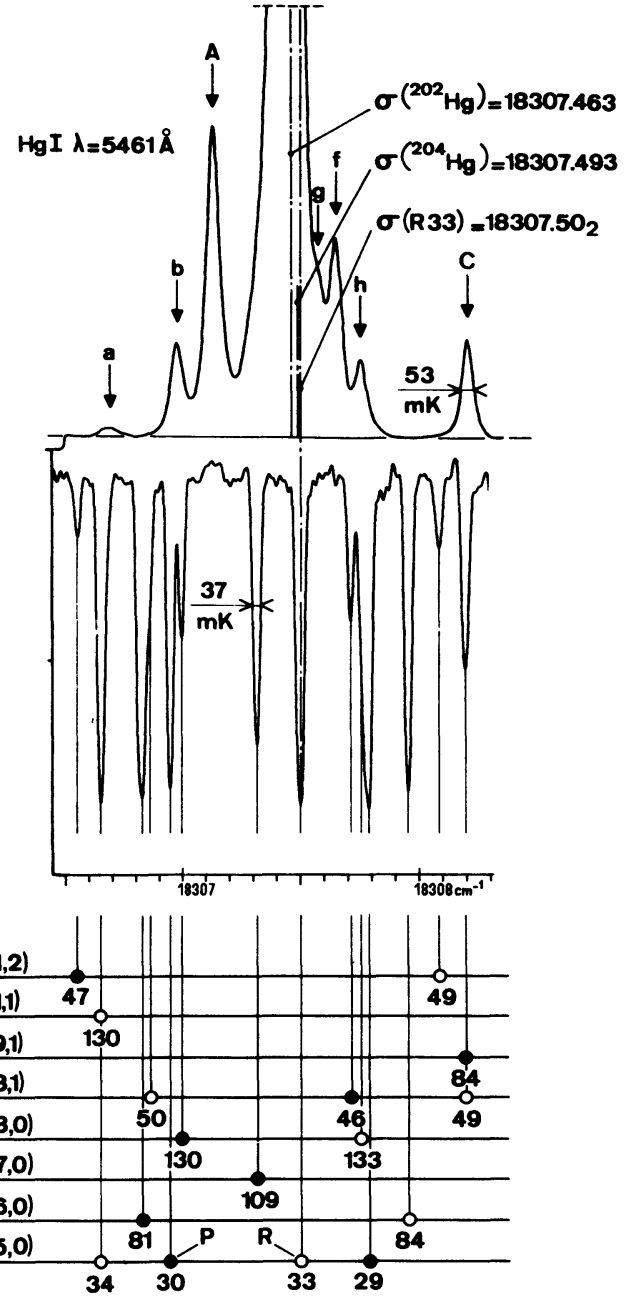

Fig. 2. - Relative position of the spectrum of the hyperfine structure of the mercury green line and the iodine absorption spectrum (see text).

b) observed absorption spectrum within the green line profile, when a cell $10 \mathrm{~cm}$ long $(l=0.1 \mathrm{~m})$ containing iodine vapour at about 0.26 torr (room temperature) is interposed between the Phillips lamp and the Fourier spectrometer;

c) same condition as in $b$ ), but the length of the cell was increased by a factor $10(l=1 \mathrm{~m})$.

The absolute value of the wavenumber of the $\sigma_{\mathrm{A}}\left({ }^{199} \mathrm{Hg}\right)$ hyperfine component being $18307.143 \mathrm{~cm}^{-1}$ [13], it follows from figures $3 b$ and $3 c$, that the wavenumber of the $\mathrm{R} 33(25,0)$ transition is equal to $(18307.143(5)+0.361(5)) \mathrm{cm}^{-1}=18307.504(10) \mathrm{cm}^{-1}$, in excellent agreement with the calculated value $18307.5025 \mathrm{~cm}^{-1}$.

6. Discussion. - The absolute wavenumber determinations of the $\mathrm{R} 33(25,0)$ line based on :

i) the direct Fourier absorption spectrum published in the atlas $[7,15]$ where $\sigma(\mathrm{R} 33)=18307.504 \pm$ $0.002 \mathrm{~cm}^{-1}$

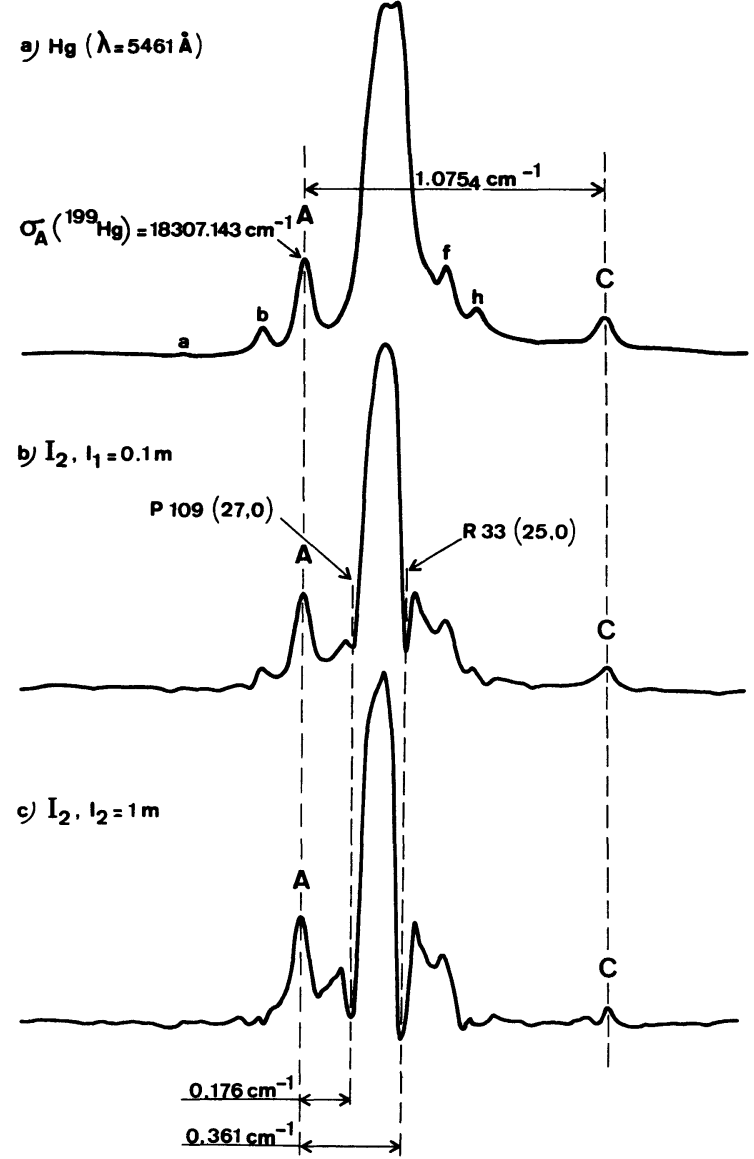

Fig. 3. $-a$ ) Profile of the mercury green line emitted by a Phillips low pressure mercury lamp. $b$ ) Observed absorption in the green line throughout a $10 \mathrm{~cm}$ long iodine cell. $c$ ) Observed absorption throughout a $1 \mathrm{~m}$ long iodine cell.

ii) the measurement of the distance between an hyperfine component of the mercury green line and the $\mathrm{R} 33$ line (this work) where $\sigma(\mathrm{R} 33)=18307.5041 \pm$ $0.010 \mathrm{~cm}^{-1}$;

iii) the molecular constants of tables III and IV where $\sigma(\mathrm{R} 33)=18307.5025 \mathrm{~cm}^{-1}$ (Table V), agree within $0.0015 \mathrm{~cm}^{-1}$.

The origin of these three results comes from studies in absorption, while the resonance data are obtained from emission studies. Are the measurements in absorption and emission equivalent ? Indeed, in the iodine case, it may happen that the intensity distribution of the hyperfine components ( 21 or 15 components depending on the parity of the line [8]) within iodine lines are not the same in emission and in absorption. As a result, the emission and absorption peaks of the iodine lines do not exactly coincide and a spurious discrepancy between the measured wavenumbers in emission and in absorption can occur. But as a good agreement is observed between the experimental wavenumbers of the resonance lines connected to the $v^{\prime \prime}=6,8,10,11,12,13,15,17$ vibrational levels and those calculated $a$ priori by means of the molecular constants (Table V), the expected discrepancy is 
only a few thousandth of $\mathrm{cm}^{-1}$. Nevertheless, this point worths a more careful examination in the future.

Another possibility for the observed discrepancy could lie in the fact that weak absorption lines are blended with the R33, P35 $\left(25, v^{\prime \prime}\right)$ lines; this effect, in the case of the $R 33(25,0)$ line, is highly improbable since the absorption lines connected to the $v^{\prime \prime}=1$ and $v^{\prime \prime}=2$ levels, located in the vicinity of the R33 line, do not coincide with this line as shown in the bottom of figure 1 .

To conclude, at the present state of our analysis, the result of $\mathbf{R}$. and $\mathrm{B}$. must be partially corrected : in particular the wavenumber of the "ladder " line of the mercury green line must be shifted by an amount of $0.032 \mathrm{~cm}^{-1}$ which is twice the quantity suggested earlier in the analysis made by Le Roy [4].

In a previous work [6] we analysed four bands $\left(0, v^{\prime \prime}\right)$ with $11 \leqslant v^{\prime \prime} \leqslant 14$. Thus we have a total of nine bands of the $\left(0, v^{\prime \prime}\right)$ type (a $v^{\prime \prime}$ progression) with $11 \leqslant v^{\prime \prime} \leqslant 19$, connected to the ground level $v^{\prime}=0$ of the B state. The molecular constants of the $v^{\prime}=0$ level based on the global fit of these data are also given in table IV. The standard deviation (S.D.) between calculated and measured wavenumbers belonging to the $\left(0, v^{\prime \prime}\right)$ progression is between 0.002 and $0.003 \mathrm{~cm}^{-1}$ (reference [6], Table I, last column). These S.D. are comparable to the observed ( $\sigma_{\text {exp }}^{\text {F.P. }}-$ $\sigma_{\text {cal }}^{\text {Fourier }}$ ) differences (Table V), for $11 \leqslant v^{\prime \prime} \leqslant 17$, as it should be expected. For $v^{\prime \prime}=18$, the agreement is less satisfactory since the resonance lines are weak and the lines connected to the $v^{\prime \prime}=19$ were not observed [2]. To summarize, in the absence of absolute measurements of iodine transitions in the near infrared region the good agreement between the S.D. (equal to $\left.\left(\sigma_{\text {exp }}^{\text {Fourier }}-\sigma_{\text {cal }}^{\text {Fourier }}\right)\right)$ and the $\left(\sigma_{\text {exp }}^{\text {F.P. }}-\sigma_{\text {cal }}^{\text {Fourier }}\right)$ values constitutes, until now, the best support that the calculated wavenumbers in the $11600-12600 \mathrm{~cm}^{-1}$ region, are actually reliable values.

7. Conclusion. - Although analysis of the ground state $X$ of the iodine was made several times in the past $[1-4,16]$ the molecular constants deduced from extensive Fourier spectroscopy measurements in absorption appear to us to be the most reliable data, unfortunately limited to the twenty first vibrational levels. Our study shows also that for $v^{\prime \prime} \geqslant 6$ the wavenumbers of the Wood's resonance series measured by means of Fabry-Perot etalons [2] are in good agreement with those deduced from the Fourier data ; however the wavenumbers of the first members $\left(v^{\prime \prime} \leqslant 5\right)$ of these series must be corrected. Finally, a precise determination of the molecular constants of the $v^{\prime}=0$ level of the excited B state, based on the analysis of a $\left(0, v^{\prime \prime}\right)$ progression of nine bands $\left(11 \leqslant v^{\prime \prime} \leqslant 19\right)$ is presented. This result, added to the recent study of the $\mathrm{B}$ state up to $v^{\prime}=80$ [17], will enable us to undertake in a near future, the complete description of the B state from the ground level up to the dissociation limit.

\section{References}

[1] Rank, D. H. and RaO, B. S., J. Mol. Spectrosc. 13 (1964) 34

[2] Rank, D. H. and Baldwin, W. M., J. Chem. Phys. 19 (1951) 1210.

[3] Tellinghuisen, J., McKeever, M. R. and Abha Sur, J. Mol. Spectrosc. 82 (1980) 222.

[4] Le Roy, R. J., J. Chem. Phys. 52 (1970) 2683.

[5] Hutson, J. M., Gerstenkorn, S., Luc, P. and SinZELLE, J., J. Mol. Spectrosc. (1982, to appear).

[6] Gerstenkorn, S., Luc, P. and Sinzelle, J., J. Physique 41 (1980) 1419.

[7] Gerstenkorn, S. and Luc, P., Atlas du spectre d'absorption de la molécule de l'iode $14800-20000 \mathrm{~cm}^{-1}$ (Editions du C.N.R.S.) 1978.

[8] Kroll, M. and INNES, K. K., J. Mol. Spectrosc. 36 (1970) 295.

[9] Gerstenkorn, S., Luc, P. and Vergès, J., J. Phys. B 14 (1981) L-193.
[10] Albritton, D. L., Harrop, W. J., Schmeltekopf, A. L. and ZARE, R. N., J. Mol. Spectrosc. 46 (1973) 25.

[11] Hutson, J. M., J. Phys. B 14 (1981) 851.

[12] GerstenkoRn, S., Rapport Département de Chimie, SECA no 110 (C.E.A. Fontenay-aux-Roses). Mars 1970.

[13] Burns, K. and Adams, K., J.O.S.A. 42 (1952) 56.

[14] BurnS, K. and AdAmS, K., J.O.S.A. 42 (1952) 716.

[15] Gerstenkorn, S. and Luc, P., Revue Phys. Appl. 14 (1979) 791.

[16] Martin, F., Churassy, S., Bacis, R., Field, R. W. and VERGÈS, J. (in preparation).

[17] Gerstenkorn, S. and Luc, P., Laser Chemistry no 3 (to appear, 1982). 